\title{
KORELASI ANTARA PERSEPSI PENGELOLAAN DAN LAYANAN PUSTAKA DENGAN MOTIVASI BELAJAR DI DIGITAL LIBRARY UNY
}

\author{
Muh. Ihwan Rosyadi, Suyantiningsih \\ Jurusan Kurikulum dan Teknologi Pendidikan FIP UNY \\ e-mail: muhihwanrosyadi@gmail.com, suyantiningsih@uny.ac.id
}

\begin{abstract}
Abstrak
Penelitian ini bertujuan untuk: (1) mengetahui tingkat pengelolaan pustaka di Digital Library, (2) mendeskripsikan tingkat layanan pustaka di Digital Library, (3) menginvestigasi tingkat motivasi belajar mahasiswa FIP terhadap Digital Library, (4) mengetahui korelasi antara pengelolaan pustaka dengan motivasi belajar di Digital Library, dan (5) mengetahui korelasi antara layanan pustaka dengan motivasi belajar di Digital Library. Jenis penelitian yang dilakukan dalam penelitian ini adalah kuantitatif korelasional, menggunakan metode korelasi product moment. Sampel dalam penelitian ini adalah pemustaka (mahasiswa) yang sedang menempuh gelar sarjana S1 dengan target presentase 15\% dari program studi yang ada di Fakultas Ilmu Pendidikan UNY. Hasil penelitian menunjukkan bahwa: (1) tingkat pengelolaan pustaka di Digital Library senilai 3,2 kategori sangat tinggi, (2) tingkat layanan pustaka di Digital Library senilai 3,1 termasuk dalam kategori sangat tinggi, (3) tingkat motivasi belajar mahasiswa FIP terhadap Digital Library senilai 3,1 kategori sangat tinggi, (4) korelasi pengelolaan pustaka dengan motivasi belajar berdasarkan teori Pearson Corelation nilai significancy menunjukan $(p=0,000<0,05)$. Hal ini membuktikan bahwa hubungan kedua variabel adalah positif. (5) korelasi layanan pustaka dengan motivasi belajar berdasarkan teori Pearson Corelation nilai significancy menunjukan $(p=0,000<0,05)$, dengan demikian hal ini membuktikan bahwa hubungan kedua variabel adalah positif.
\end{abstract}

Kata Kunci: persepsi, pengelolaan, layanan, pustaka, motivasi belajar.

\section{CORRELATION BETWEEN THE PERCEPTION OF LITERATURE MANAGEMENT AND SERVICES WITH LEARNING MOTIVATION IN DIGITAL LIBRARY UNY}

\begin{abstract}
This study aims to: (1) determine the level of library management in the Digital Library, (2) describe the level of library services in the Digital Library, (3) investigate the motivation level of student learning towards the Digital Library, (4) find out the correlation between library management and motivation of learning in the Digital Library, and (5) knowing the correlation between library services with motivation of learning in the Digital Library. This type of research conducted in this study is quantitative correlational, using the product moment correlation method. The sample in this study is the user (student) who is pursuing a bachelor's degree with a target percentage of $15 \%$ of the existing study programs at the Faculty of Education UNY. The results showed that: (1) the level of library management in the Digital Library worth 3.2, categories is very high, (2) the level of library service in the Digital Library worth 3.1 is included in the very high category, (3) the level of students' motivation of learning towards Digital Library worth 3.1 categories is very high, (4) correlation of library management with learning motivation based on the Pearson Corelation theory significance value shows ( $p=0,000<0.05$ ), this proves that the relationship between the two variables is positive, (5) correlation of library services with motivation of learning based on the Pearson Correlation theory significance value shows $(p=0,000<0.05)$, thus this proves that the relationship between the two variables is positive.
\end{abstract}

Keywords: perception, management, services, literatures, motivation of learning.

\section{PENDAHULUAN}

Berdasarkan Undang-Undang Nomor 43 Tahun 2007 tentang perpustakaan disebutkan bahwa perpustakaan merupakan institusi pengelola karya tulis, karya cetak, dan/atau karya rekam secara profesional dengan sistem yang baku untuk memenuhi kebutuhan pendidikan, penelitian, pelestarian, informasi dan rekreasi para pemustaka. (Bab I ayat 1). Lebih lanjut dijelaskan dalam Bab V Pasal 14 Ayat 3, bahwa setiap perpustakaan mengembangkan layanan perpustakaan sesuai dengan kemajuan teknologi informasi dan komunikasi. 
Menurut Ranganathan (dalam Zulaikah, 2010), perpustakaan merupakan organisasi yang tumbuh "growing organism". Kemajuan perpustakaan berbasis teknologi informasi dan komunikasi dengan pengembangan perpustakaan tersebut merupakan tuntutan masyarakat sekaligus kebutuhan zaman. Pemustaka (mahasiswa) dalam belajar berharap mendapatkan yang diinginkan dari sumber belajar (Digital Library) tersebut, pengelolaan dan layanan yang diharapkan harus ditemukan oleh pemustaka dan dilayankan dari pihak pengelola.

Berdasarkan observasi awal yang dilakukan di Digital Library UNY, diketahui bahwa ruang belajar pengunjung yang seharusnya kedap suara, oleh pengguna masih terdengar kebisingan dari luar. Selain itu, kapasitas meja dan kursi serta komputer online yang digunakan sebagai penelusuran referensi/koleksi digital masih terbatas, sehingga banyak mahasiswa kecewa dan jenuh menunggu antrian. Lebih lanjut ditemukan bahwa, komputer online di Digital Library masih sering terjadi ketika mahasiswa melakukan penelusuran referensi/koleksi digital.

Dalam hal ini, mahasiswa mengakui adanya keterbatasan akses pada komputer yang telah disediakan oleh Digital Library terkait pencarian referensi/koleksi digital dikarenakan koleksi digital selain e-prints dan e-journal tidak bisa diakses oleh pengguna kecuali dengan cara datang langsung ke Digital Library atau menggunakan jaringan internet yang disediakan oleh UNY.

Permasalahan yang berhasil dihimpun berdasarkan observasi awal tersebut, diketahui memiliki dampak besar terhadap kemudahan dalam mengakses berbagai informasi. Di lain pihak, pelayanan Digital Library juga berperan penting bagi pengguna. Dalam hal ini, terkait dengan kompetensi petugas Digital Library dalam hal layanan, diketahui bahwa petugas masih belum optimal terutama ketika dalam melayani pengguna. Kendala yang dialami oleh pengguna diantaranya adalah stop kontak listrik yang disediakan bagi pengunjung Digital Library yang membawa laptop sendiri masih terbatas jumlahnya.

Berdasarkan pada beberapa permasalahan tersebut, maka peneliti tertarik untuk mengetahui ada tidaknya korelasi antara kualitas pengelolaan dan layanan pustaka di Digital Library dengan motivasi belajar mahasiswa. Sebagaimana diketahui bahwa penyediaan layanan Digital Library oleh lembaga dimaksudkan agar mahasiswa termotivasi untuk mengunjunginya dengan harapan bahwa meningkatnya motivasi belajar mahasiswa akan berkorelasi positif terhadap kemajuan belajarnya.

\section{METODE}

Jenis penelitian dalam penelitian ini adalah kuantitatif korelasional. Menurut Sugiyono (2014: 87), metode korelasi adalah metode pertautan atau metode penelitian yang berusaha menghubung-hubungkan antara satu unsur/elemen dengan unsur/elemen lain untuk menciptakan bentuk dan wujud baru yang berbeda dengan sebelumnya.

Desain penelitian ini menggunakan penelitian survei. Kerlinger (dalam Sugiyono, 2012:7) mengemukakan bahwa penelitian survei adalah penelitian yang dilakukan pada populasi besar dan kecil, tetapi data yang dipelajari adalah data dari sampel yang diambil dari populasi tersebut, sehingga ditemukan kejadian relatif distribusi, dan hubungan antar variabel sosiologis maupun psikologis

\section{Tempat dan Waktu Penelitian}

Penelitian ini dilaksanakan di Kampus Sarjana S-1 Fakultas Ilmu Pendidikan Universitas Negeri Yogyakarta di Jl. Colombo No. 1, Karangmalang, Sleman, Yogyakarta. Penelitian ini dilaksanakan pada 5 September 2019 hingga 29 Oktober 2019.

\section{Subjek Penelitian}

Populasi dalam penelitian ini adalah seluruh pemustaka (mahasiswa) yang sedang menempuh gelar Sarjana S1 pada Fakultas Ilmu Pendidikan UNY yang berjumlah 2.520. Adapun sampel dalam penelitian ini adalah pemustaka (mahasiswa) yang sedang 
menempuh gelar sarjana S1 dengan target presentase $15 \%$ dari program studi yang ada di Fakultas Ilmu Pendidikan UNY. Program studi tersebut terdiri dari Teknologi Pendidikan, Manajemen Pendidikan, Bimbingan dan Konseling, Pendidikan Luar Sekolah, Pendidikan Luar Biasa, Pendidikan Guru Sekolah Dasar, Pendidikan Anak Usia Dini, Kebijakan Pendidikan, dan Pendidikan Psikologi.

Terdapat kriteria pemustaka (mahasiswa) yang diambil sampelnya, yaitu sedang menempuh gelar sarjana S1 FIP UNY mulai dari angkatan 2016 sampai dengan 2018, kemudian pernah berkunjung ke Digital Library Universitas Negeri Yogyakarta dengan frekuensi 1-5 kali, 6-10 kali, 11-15 kali, atau $>15$.

\section{Teknik dan Instrumen Pengumpulan Data}

1. Teknik Pengumpulan Data

Pada penelitian ini peneliti menggunakan teknik pengumpulan data dengan menggunakan teknik observasi (pengamatan), teknik angket/kuesioner, dan teknik dokumentasi.

2. Instrumen Pengumpulan Data

Penelitian ini instrumen pengumpulan data yang digunakan adalah angket/kuisioner. Angket tersebut menggunakan penilaian skala likert. Menurut Sugiyono (2010: 93), skala likert diterapkan untuk mengukur persepsi, sikap, dan pendapat seseorang atau suatu kelompok manusia tentang fenomena sosial. Sedangkan menurut Hadi (1991: 19) skala likert adalah skala yang berisi lima tingkat jawaban tentang kesetujuan responden terhadap pernyataan dikemukakan yang dikemukakan melalui opsi jawaban yang telah disediakan.

Penelitian ini memodifikasi angket dengan skala likert menjadi skala 4 tingkat. Hal itu dimaksudkan untuk mengurangi kelemahan yang terdapat skala lima tingkat, yaitu meniadakan klasifikasi jawaban yang berada pada posisi netral atau ditengah. Penelitian ini menerapkan 4 alternatif jawaban diantaranya adalah sangat tidak setuju (STS), tidak setuju (TS), setuju (S), dan sangat setuju (SS). Responden berhak memilih salah satu dari 4 alternatif jawaban yang telah disesuaikan dengan kondisi subyek. Berikut adalah tabel yang menggambarkan skor pada setiap skala likert.

Tabel 1. Skor Alternatif Jawaban Instrumen

\begin{tabular}{ll}
\hline $\begin{array}{l}\text { Pernyataan Positif }(+) \\
\text { (Alternatif Jawaban) }\end{array}$ & Skor \\
\hline Sangat Tidak Setuju (STS) & 1 \\
Tidak Setuju (TS) & 2 \\
Setuju (S) & 3 \\
Sangat Setuju (SS) & 4 \\
\hline
\end{tabular}

\section{Validitas dan Reliabilitas Data}

1. Uji Validitas Instrumen

Uji validitas penelitian ini dapat menggunakan teknik korelasi product moment dari Karl Pearson yang rumusnya yaitu:

$$
r_{x y}=\frac{n\left(\sum X Y\right)-\left(\sum X \cdot \sum Y\right)}{\sqrt{\left[n \sum X^{2}-\left(\sum X\right)^{2}\right] \cdot\left[n \sum Y^{2}-\left(\sum Y\right)^{2}\right]}}
$$

Keterangan:

$r_{x y} \quad:$ Koefisien korelasi antara $\mathrm{x}$ dan $\mathrm{y}$

$n \quad$ : Jumlah responden

$\sum X Y:$ Jumlah perkalian $\mathrm{X}$ dan $\mathrm{Y}$

$\sum X \quad$ : Jumlah skor $\mathrm{X}$

$\sum Y \quad$ : Jumlah skor $\mathrm{Y}$

$\sum X^{2}$ : Jumlah kuadrat skor $\mathrm{X}$

$\sum Y^{2}$ : Jumlah kuadrat skor $\mathrm{Y}$

2. Uji Reliabilitas Instrumen

Menurut Arikunto (2010:239), pengujian dari pencarian reliabilitas dapat menerapkan rumus Alpha Cronbach sebagai berikut:

$$
r_{n}=\left[\frac{k}{k-1}\right]\left[i-\frac{\sum \sigma_{b}^{2}}{\sigma_{t}^{2}}\right]
$$

Keterangan:

$r_{n} \quad=$ koefisien reliabilitas instrument yang dicari

$k=$ banyak butir soal

$\sum \sigma_{b}^{2}=$ jumlah variansi nilai butir soal ke-i 
$\begin{aligned} i & =1,2,3, \ldots \mathrm{n} \\ \sigma_{t}^{2} & =\text { variansi total }\end{aligned}$

Instrumen disebut reliabel jika memiliki koefisien reliabel senilai 0,6 atau lebih. Sedangkan instrumen yang nilai koefisiennya dibawah 0,6 maka instrument tersebut disebut tidak reliabel.

\section{Teknik Analisis Data}

Teknik analisis data pada penelitian ini menggunakan teknik korelasi Karl Pearson dan korelasi ganda. Tetapi sebelum menggunakan metode tersebut, dicari dulu skor baku ( $\left.\mathrm{T}_{\text {score }}\right)$ masing-masing data. Menurut Nar Heryanto dan Akib Hamid (2003) bahwa $\mathrm{T}_{\text {score }}$ berfungsi untuk menyetarakan dari beberapa jenis skor yang berbeda satuan ukurannya atau berbeda bobot skornya, menjadi skor baku atau skor standar.

$$
T_{\text {score }}=50+10 . Z_{s}
$$

Keterangan:

$\mathrm{T}_{\text {score }}$ : skor baku

$Z_{\text {score }}:$ diperoleh dari perhitungan $Z_{\text {score }}$ $Z_{\text {score }}=\frac{X_{i}-\bar{X}}{S D}$

Kemudian dilakukan analisis data untuk mengetahui hubungan antara variabel $X_{1}$ dan $\mathrm{X}_{2}$ sebagai variabel bebas dengan variabel $\mathrm{Y}$ sebagai variabel terikat, melalui perhitungan koefisien korelasi. Setelah data tes memiliki nilai baku yang sama, maka data menggunakan uji korelasi product moment dan korelasi ganda, dengan rumus sebagai berikut:

\section{Mencari Koefisien Korelasi}

Korelasi product moment dan korelasi ganda dapat digunakan mengetahui hubungan antara variabel bebas dan variabel terikat. Menurut Sudjana (2005: 369), koefisien korelasi antara variabel $\mathrm{X}_{1}$ dengan $\mathrm{Y}$, dan $\mathrm{X}_{2}$ dengan $\mathrm{Y}$ dapat dicari dengan menggunakan rumus korelasi Carl Pearson:

$$
\mathrm{r}_{X_{i} Y}=\frac{n \sum X_{i} Y-\left(\sum X_{i}\right)\left(\sum Y\right)}{\left.\sqrt{\left\{n \sum X_{i}^{2}\right.}-\left(\sum X_{i}\right)^{2}\right\}\left\{n \sum Y^{2}-\left(\sum Y\right)^{2}\right\}}
$$

Keterangan:

$\mathrm{r}_{X_{i} Y}=$ Koefisien korelasi

$\mathrm{n}=$ Jumlah sampel

$\mathrm{X}=$ Skor variabel $\mathrm{X}$

$\mathrm{Y}=$ Skor variabel $\mathrm{Y}$

$\sum \mathrm{X}=$ Jumlah skor variabel $\mathrm{X}$

$\sum \mathrm{Y}=$ Jumlah skor variabel $\mathrm{Y}$

$\sum X^{2}=$ Jumlah kuadrat skor variabel $\mathrm{X}$

$\sum Y^{2}=$ Jumlah kuadrat skor variabel $\mathrm{Y}$

Untuk mengetahui apakah koefisien korelasi hasil perhitungan signifikan atau tidak, maka perlu dibandingkan dengan $r$ tabel Product Moment, dengan taraf signifikan 0,05 (taraf kepercayaan 95\%). Kaidah pengujian signifikan : Jika $r_{\text {hitung }} \geq r_{\text {tabel }}$, maka tolak Ho artinya ada hubungan yang signifikan dan jika $r_{\text {hitung }}<r_{\text {tabel}}$, maka terima Ho artinya tidak ada hubungan yang signifikan.

Menurut Sudjana (2005:369), untuk mengetahui hubungan variabel $\mathrm{X}$ terhadap $\mathrm{Y}$ dicari dengan menggunakan rumus koefisien determinasi. Rumus koefisien determinasi sebagai berikut:

$$
K P=r^{2} \times 100 \%
$$

Keterangan:

$\mathrm{KP}=$ Nilai koefisien determinasi

$r^{2}=$ Koefisien korelasi dikuadratkan.

\section{Mencari Korelasi Ganda}

Untuk Mencari hubungan kedua variabel bebas dengan variabel terikat dengan menggunakan rumus korelasi ganda $\left(R_{x_{1} x_{2}} Y\right)$

$$
R_{X_{1} X_{2} Y}=\sqrt{\frac{r_{X_{1}}^{2}+2\left(r_{X_{1} Y}\right)\left(r_{X_{2} Y}\right)\left(r_{X_{1} X_{2}}\right)}{1-r_{X_{1} X_{2}}^{2}}}
$$

Keterangan:

$R_{X_{1} X_{2} Y}=$ Koefisien korelasi ganda antar variabel $X_{1}$ dan $X_{2}$ Secara bersamaan dengan variabel Y. 
$r_{X_{1} Y}=$ Koefisien korelasi $\mathrm{X}_{1}$ terhadap $\mathrm{Y}$

$r_{X_{2} Y}=$ Koefisien korelasi $\mathrm{X}_{2}$ terhadap $\mathrm{Y}$

$r_{X_{1} X_{2}}=$ Koefisien korelasi $X_{1}$ terhadap $X_{2}$

Untuk mengetahui partisipasi kedua variabel bebas dengan variabel terikat, maka koefisien determinasi dicari dengan mengalikan koefisien korelasi ganda yang telah dikuadratkan $\left(\mathrm{R}^{2}\right)$ dengan $100 \%$.

\section{HASIL DAN PEMBAHASAN}

\section{Hasil}

A. Uji Instrumen Validitas Dan Reliabilitas

1. Uji Validitas

Menurut Sugiyono (2012: 121) untuk mengukur validitas kuesioner yang diberikan kepada responden maka digunakan rumus korelasi Produk Moment. Item pertanyaan dinyatakan valid apabila memiliki $r$ hitung $>r$ tabel atau sig $<0.05$.

Besarnya nilai r-hitung dari seluruh butir >0,138. Dengan demikian dapat disimpulkan bahwa seluruh butir dinyatakan valid dan kuisioner dalam penelitian ini dapat digunakan untuk analisis selanjutnya yaitu korelasi Pearson.

2. Uji Reliabilitas

Teknik yang digunakan menurut Ghozali (2011: 48) untuk mengukur konsistensi internal dalam penelitian ini dengan teknik Cronbach's alpha. Hasil pengujian reliabilitas dapat ditunjukkan pada tabel berikut:

Tabel 2. Hasil Uji Reliabilitas

\begin{tabular}{lccc}
\hline \multicolumn{1}{c}{ Variabel } & $\begin{array}{c}\text { Alpha } \\
\text { Crobach }\end{array}$ & $\begin{array}{c}\text { Nilai } \\
\text { kritis }\end{array}$ & Keterangan \\
\hline $\begin{array}{l}\text { Pengelolaan } \\
\text { Digital }\end{array}$ & 0.832 & 0.6 & reliabel \\
$\begin{array}{l}\text { Library } \\
\text { Layanan }\end{array}$ & & & \\
$\begin{array}{l}\text { Digital } \\
\text { Library } \\
\text { Motivasi }\end{array}$ & 0.882 & 0.6 & reliabel \\
$\begin{array}{l}\text { Belajar } \\
\text { Mahasiswa }\end{array}$ & 0.844 & 0.6 & reliabel \\
\hline $\begin{array}{l}\text { Sumber: Data primer diolah, 2019 } \\
\end{array}$
\end{tabular}

Berdasarkan ringkasan hasil uji reliabilitas seperti yang terangkum dalam Tabel 2. di atas, dapat diketahui bahwa nilai koefisien Cronbach Alpha seluruh varaibel penelitian lebih besar dari 0,6. Dengan mengacu pada pendapat yang dikemukakan oleh Ghozali (2011: 48) maka semua butir pertanyaan dalam variabel penelitian adalah handal.

\section{Pembahasan}

1. Tingkat Persepsi Mahasiswa FIP tentang Pengelolaan Pustaka Digital Library UNY

Hasil penelitian dari data kuisioner menyatakan bahwa persepsi mahasiswa terhadap pengelolaan pustaka di Digital Library UNY termasuk kategori sangat tinggi, sehingga dapat dikatakan telah memadai. Hal tersebut didasarkan pada hasil nilai jumlah rata-rata keseluruhan dari tingkat persepsi mahasiswa FIP tentang pengelolaan pustaka Digital Library yang menunjukkan angka 3,2.

Kesesuaian dalam ilmu teknologi pendidikan pada kawasan pengelolaan yaitu berkaitan dengan pengelolaan Digital Library yang mengacu pada perencanaan, pengendalian, penyimpanan, dan pengolahan informasi. Diciptakannya Digital Library bertujuan untuk memfasilitas proses belajar mahasiswa. Kualitas pengelolaan pustaka Digital Library harus selalu dioptimalkan, karena mengingat sebagai salah satu dari pusat sumber belajar, dan memiliki perkembangan teknologi yang baik.

Persepsi mahasiswa sebagai pemustaka terhadap tingkat kualitas pengelolaan Digital Library dibentuk yang berawal dari pengamatan, merasakan, dan menggunakannya. Pengelolaan Digital Library dapat diketahui juga dibuat dengan pedoman prosedur yang sangat baik, tetapi dalam implementasinya juga harus dilakukan secara optimal sehingga dapat tercipta sesuai ketepatan tujuan yang efektif dan efisien. 
Hasil tersebut sesuai yang diungkapkan oleh Adisasmita (2011: 22) mengemukakan bahwa pengelolaan bukan hanya melaksanakan suatu kegiatan, akan tetapi merupakan rangkaian kegiatan yang meliputi fungsi-fungsi manajemen, seperti perencanaan, pelaksanaan, dan pengawasan untuk mencapai tujuan secara efektif dan efisien.

2. Tingkat Persepsi Mahasiswa FIP tentang Layanan Pustaka Digital Library

Berdasarkan hasil penelitian yang diperoleh dari data kuisioner diketahui bahwa layanan pustaka yang dilakukan oleh Digital Library UNY menurut persepsi mahasiswa masuk dalam kategori sangat baik, sehingga bisa disebut memadai. Hal tersebut dinyatakan dengan hasil nilai jumlah rata-rata keseluruhan dari tingkat persepsi mahasiswa FIP tentang layanan pustaka Digital Library UNY menunjukkan angka 3,1 yang merupakan masuk dalam kategori sangat tinggi.

Indikator layanan Digital Library yang baik pertama adalah kecepatan. Akses pencarian referensi/koleksi digital secara online dapat berjalan cepat dan mudah dibuktikan dengan nilai rata-rata 3,1 masuk kategori sangat tinggi. Kedua, ketepatan, dan kemudahan tata cara pemakaian komputer yang telah disediakan. Beberapa hal yang masih perlu diperbaiki adalah pengguna masih belum familiar dengan komputer iMac bersistem operasi MacOS yang disediakan oleh Digital Library karena berbeda pengoperasiannya dengan Windows, sehingga perlu petunjuk yang disediakan dan bias diakses oleh pengguna.

Ketiga tentang keamanan, hal ini terkait dengan perlunya peningkatan keamanan bagi kendaraan bagi pengunjung Digital Library yang memadai dan terjaga seperti dilengkapi CCTV dan keluar masuk tempat parkir menggunakan sistem tiket yang disinkronasikan dengan kartu identitas.

Keempat tentang keramah-tamahan, yakni terkait dengan komunikasi petugas baik dalam merespon kritik/keluhan pengguna layanan Digital Library meskipun berdasarkan hasil penelitian termasuk dalam kategori tinggi tetapi perlu dioptimalkan terutama dalam menanggapi kritik atau keluhan dari pengguna.

Kelima tentang kenyamanan yang termasuk dalam kategori tinggi. Hal ini berkaitan dengan kebersihan ruangan. Namun beberapa hal yang perlu diperhatikan adalah bahwa bagi pengunjung yang membawa laptop sendiri memerlukan stop kontak, sedangkan stop kontak yang disediakan jumlahnya masih terbatas, sehingga merepotkan pengguna, dan pengguna perlu mempersiapkan steker bercabang sendiri dari tempat tinggal agar dapat ikut mengisi baterai laptopnya, hal ini membuat kurang efektif dan efisien.

Berdasarkan hal tersebut perlu lebih ditingkatkan atau dioptimalkan dalam layanannya karena masih terdapat layanan yang nilainya belum termasuk dalam kategori sangat tinggi.

3. Tingkat Motivasi Belajar Mahasiswa sebagai Pemustaka Digital Library

Hasil penelitian menyatakan bahwa jumlah rata-rata keseluruhan dari tingkat motivasi belajar mahasiswa FIP sebagai pemustaka Digital Library UNY menunjukkan angka 3,1 dan termasuk dalam kategori sangat tinggi. Tingkat motivasi juga berdampak terhadap intensitas kunjungan ke Digital Library.

Berdasarkan data yang dihimpun dapat diketahui bahwa subyek penelitian tersebut berjumlah 265 mahasiswa, frekuensi kunjungan mahasiswa yang berada pada rentang 1-5 kali terdapat 204 mahasiswa, kemudian 6-10 kali berjumlah 30 mahasiswa, dan 11-15 berjumlah 20 mahasiswa, serta kunjungan yang lebih dari 15 kali berjumlah 11 mahasiswa. Data tersebut juga sebagai jaminan bahwa responden (mahasiswa) yang diambil datanya pernah melakukan atau memanfaatkan Digital Library UNY. 
Motivasi belajar yang timbul disebabkan oleh adanya pengelolaan dan layanan Digital Library yang baik sebagai salah satu alternatif pusat sumber belajar yang efektif dan efisien dalam memperluas wawasan, kelengkapan koleksinya yang dapat diakses secara gratis, pengelolaan dan layanan pustaka yang memiliki kualitas sangat tinggi dengan perkembangan teknologi yang baik, ditambah didukung tersedianya iMac bagi pengunjung, maka membuat mahasiswa semakin sering berkunjung untuk semangat memperbarui pengetahuan dalam dirinya.

\section{Korelasi Pengelolaan Pustaka Digital Library Dengan Motivasi Belajar Mahasiswa}

Hasil penelitian menyatakan bahwa terdapat hubungan antara pengelolaan Digital Library dengan motivasi belajar mahasiswa, dengan nilai signifikansi menunjukan $(\mathrm{p}=0,000<0,05)$. Nilai Pearson Correlation dalam analisis ini bernilai negatif yang membuktikan hubungan antara kedua variabel tersebut bersifat positif atau dengan kata lain semakin bagus pengelolaan Digital Library maka berimplikasi pada meningkatnya motivasi belajar mahasiswa.

Keterkaitan dengan motivasi belajar dengan kesesuaian harapan pada pengelolaan yang dilakukan Digital Library tersebut menyebabkan mahasiswa/pengunjung tidak mengalami kejenuhan untuk berada didalamnya bahkan semakin termotivasi untuk semakin giat belajar dan menggali lebih banyak lagi ilmu pengetahuan sehingga mahasiswa tidak akan ketinggalan dengan perkembangan teknologi serta mampu untuk turut serta didalamnya dalam rangka mencapai tujuan kehidupan yang sebenarnya yaitu mencapai sebuah kesuksesan.

Keterkaitan lain dari pengelolaan Digital Library dengan motivasi belajar mahasiswa/pengunjung dapat dilihat dari adanya pengembangan materi pembelajaran yang selalu berkembang dan tidak menutup kemungkinan bagi mahasiswa untuk membutuhkan literatur elektronik pelengkap lain yang belum dimilikinya sehingga mahasiswa membutuhkan sarana untuk mendapatkan literatur tersebut yang dalam hal ini adalah Digital Library.

Pentingnya Digital Library sebagai sarana pendidikan dan motivasi belajar sebagai sarana untuk mencapai keberhasilan pembelajaran maka sudah sewajarnya apabila Digital Library dikelola dengan baik di setiap aspeknya, baik pengadaan bahan pustaka maupun mengelolanya. Apabila salah satu dari pengelolaan kurang mendapatkan perhatian maka akan mengganggu fungsi Digital Library sebagai salah satu pusat sumber belajar.

Berdasarkan uraian tersebut maka dapat disimpulkan bahwa dengan pengelolaan Digital Library baik sebagai salah satu pusat sumber belajar berimplikasi pada meningkatkan motivasi belajar mahasiswa yang pada hakekatnya sebagian dari motivasi tersebut telah ada pada dirinya sendiri yang dikembangkannya dengan perkembangan lingkungan belajar yang ada di sekelilingnya.

5. Korelasi Layanan Pustaka Digital Library dengan Motivasi Belajar Mahasiswa

Berdasarkan penelitian, diketahui bahwa hubungan antara layanan Digital Library dengan motivasi belajar mahasiswa, dengan nilai signifikansi hasil menunjukan $(\mathrm{p}=0,000<0,05)$. Sedangkan nilai Pearson Correlation dalam analisis ini bernilai negatif yang membuktikan hubungan antara kedua variabel tersebut bersifat positif atau dengan kata lain semakin meningkat layanan Digital Library maka motivasi belajar mahasiswa meningkat.

Kualitas pelayanan harus dapat mendukung kenyamanan belajar mahasiswa sehingga pihak Digital Library 
dapat melaksanakan fungsinya dengan baik. Perguruan Tinggi dan pelayanannya, bukanlah hanya sekedar tempat orang belajar, akan tetapi jauh lebih luas karena menyangkut semua aspek-aspek yang mempengaruhi efisiensi, efektifitas dan produktivitas belajar.

Layanan Digital Library mulai dari dapat memberikan kenyaman ruang layanan, ruang belajar yang rapi bersih dan wangi, ketenangan ruang layanan, dapat memberikan kemudahan tata cara peminjaman dan pengembalian mouse serta keyboard wireless yang digunakan untuk pemakaian komputer online yang disediakan Digital Library, tidak adanya gangguan dalam antre peminjaman dan pengembalian mouse serta keyboard wireless, akses pencarian referensi/koleksi pusataka secara online dapat berjalan cepat dan mudah, keamanan tempat parkir kendaraan bagi pengguna, terdapat identitas petugas layanan, kewenangan petugas layanan.

Selain itu juga terdapat petugas disetiap ruang belajar jika dibutuhkan oleh pengguna, kepatuhan petugas terhadap jam kerja sesuai dengan ketentuan yang berlaku, kecekatan petugas dalam membantu pengguna yang mengalami kesulitan, komunikasi petugas yang baik dalam merespon kritik/keluhan pengguna, kompetensi petugas baik dalam mengatasi masalah layanan dengan pengguna, petugas juga dapat bersikap kooperatif jika terdapat masalah dengan pengguna, kelengkapan koleksi pustaka yang tersedia, memiliki kesesuaian penempatan klasifikasi koleksi pustaka dengan kategori search engine yang telah disediakan dalam program elibrary Digital Library, stop kontak listrik yang memadai bagi pengunjung/pengguna yang membawa laptop sendiri.

Keterkaitan pelayanan tersebut jika dapat dipenuhi/dilaksanakan dengan baik dapat berdampak pada motivasi belajar mahasiswa, ditambah karena layanan dari koleksi digital yang cukup lengkap serta dapat diakses secara gratis oleh pengguna, dan adanya iMac bagi pengunjung dapat menumbuhkan motivasi belajar mahasiswa sehingga terpenuhi dalam proses belajarnya dengan adanya layanan Digital Library yang baik. Hubungan yang kurang serasi antara seorang pekerja pelayanan dengan mahasiswa, prosedur dan tata kerja layanan yang tidak jelas menyebabkan kinerja yang buruk (Ratminto \& Winarsih, 2010). Dari uraian di atas dapat disimpulkan bahwa dengan kualitas pelayanan yang baik maka motivasi belajar akan meningkat pula.

\section{PENUTUP}

Berdasarkan hasil penelitian, maka dapat disimpulkan bahwa tingkat persepsi mahasiswa FIP tentang pengelolaan dan layanan pustaka Digital Library menunjukkan hasil yang baik dan termasuk dalam ketegori sangat baik. Meskipun demikian, masih terdapat poin yang nilai rata-rata belum masuk kategori sangat baik, sehingga beberapa aspek dalam pengelolaan dan layanan perlu ditindaklanjuti untuk lebih meningkatkan kualotas baik layanan maupun pengelolaan Digital Library di UNY.

\section{UCAPAN TERIMA KASIH}

Terima kasih kami sampaikan kepada pihak Digital Library UNY yang telah memberikan ijin untuk kami peneliti melakukan penelitian, sehingga harapan kami adalah kualitas layanan pada aspek-aspek yang telah kami teliti bias ditingkatkan dan memudahkan pihak Digital Library untuk mengidentifikasi beberapa hal yang masih perlu mendapatkan perhatian dan tindak lanjut.

\section{DAFTAR PUSTAKA}

Arikunto, Suharsimi. (2010). Prosedur Penelitian: Suatu Pendekatan Praktik (Edisi Revisi). Jakarta: Rineka Cipta.

Ghozali, Imam. 2011. Aplikasi Analisis Multivariate Dengan Program SPSS. Semarang: Badan Penerbit Universitas Diponegoro.

Hadi, Sutrisno. (1991). Statistik dalam Basic

Jilid 1. Yogyakarta: Andi Offset. 
Ratminto. \& Winarsih A. S. (2010). Manajemen Pelayanan (Pengembangan Model Konseptual, Penerapan Citizen's Charter dan Standar Pelayanan Minimal). Yogyakarta: Pustaka Pelajar.

Sudjana. (2005). Metode Statistika. Bandung: Tarsito.

Sugiyono. (2010). Metode Penelitian Penelitian Pendekatan Kuantitatif, Kualitatif dan $R \& D$. Bandung: Alfabeta.
Sugiyono. (2012). Metode Penelitian Kuantitatif, Kualitatif, dan Kombinasi. Bandung Alfabeta.

Zulaikah, Sri Royanti. (2010). Kontribusi Teori Ranganathan dalam Perkembangan Perpustakaan di Indonesia. Makalah disampaikan dalam Kuliah Program Pasca sarajana, UIN Sunan Kalijaga Jawa Timur. 